\title{
ALGUNAS FIGURAS MITOLÓGICAS EN QUINTO DE ESMIRNA
}

Quintus has stressed the importance of certain divinities such as Eos, Horae, and Themis, which occupy a secondary place in Homer. This paper demonstrates the innovations made by the epic poet in certain aspects (genealogy, function, vocabulary) and examines possible influences (several authors, notions of his age, etc.) upon him.

1. En líneas generales los dioses de los Posthomerica se acomodan a los moldes homéricos '. No obstante, pueden encontrarse ciertas figuras divinas y varias abstracciones divinizadas ${ }^{2}$ que se remontan a fuentes distintas ${ }^{3}$, mientras que otras tradicionales presentan algún matiz peculiar que evidencia una búsqueda de originalidad por este reconoci-

I A pesar de notas características como la insistencia en el poder del destino (debida al estoicismo) o la mengua que a veces se atisba en la autoridad de Zeus, entre otras. Pueden consultarse mis artículos «El Destino en los Posthomerica de Quinto de Esmirna», Habis 16, 1985, p. 101 ss., y «La intervención psíquica en los Posthomerica de Quinto de Esmirna», Habis 17, 1986, p. 109 ss. (y, sobre todo, n. 3). En la alegoría de 'Aperry (QS, V 49 ss., XIV 195 ss.) se han visto con razón, además de la influencia de Hesíodo ( $O p$. 287 ss.), señales neopitagóricas (cf. C. S. Byre, «Per aspera (et arborem) ad astra. Ramifications of the allegory of Arete in Quintus Smyrnaeus Posthomerica 5, 49-68», Hermes 110, 1982, p. 192 ss.), aunque la idea del nóvos en estos pasajes y a lo largo de la obra (QS, I 459 s., II 76 s., IV 87, VI 451, etc.) está de nuevo en conexión con el estoicismo (cf. $S V F$ I 47, 25; III 28, 7; Epict., Diss. I 24,1 ss.; etc.).

2 Sigo el texto de la excelente y completísima edición de F. Vian, Quintus de Smyrne. La suite d'Homère, 3 vols., París 1963-69. A menos que se especifique, la numeración de los fragmentos citados será la de las ediciones seguidas por LSJ.

${ }^{3} \mathrm{La}$ inmensa mayoría de los dioses que aparecen en los Posthomerica figuran en

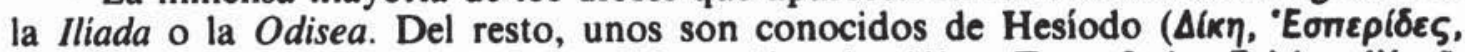

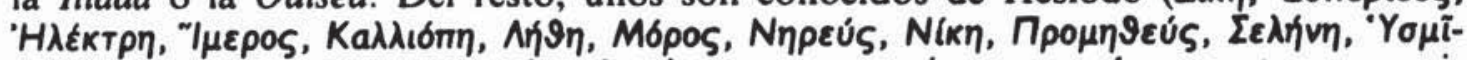
val, Фóvos, Xdos, ' $\Omega$ kupón) y los demás, en escaso número, se documentan por pri-

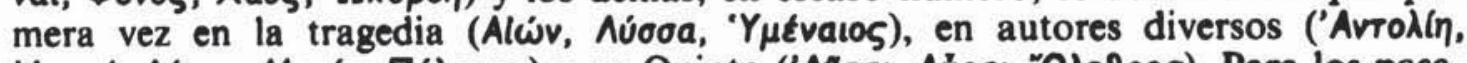

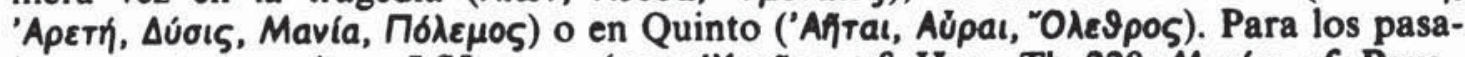
jes concretos, remito a LSJ, s. uu. (para 'Youtval, cf. Hes., Th. 228; Mavlat, cf. Paus.,

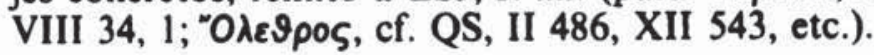


do poeta doctus. Concretamente Eos o las Horas, como bien apunta el profesor Vian ${ }^{4}$, gozan de especial relieve en el poema y a ellas dedicaré unas breves observaciones. Además añadiré un comentario respecto al papel de Temis (y, a partir de ella, de Dice) en la obra.

2. No es de extrañar que Eos cobre importancia dado que es madre de Memnón, a cuya llegada, principalía y posterior muerte está dedicado el $\lambda 6$ yos $\beta$ '. Si para Hesíodo (Th. 371 ss.) esta diosa nace de $\mathrm{Hi}$ perión y Tía (o Tea), hermana, por tanto, de Helio y Selene (en el $h$. Hom. XXXI 4 ss., el único cambio es la madre, Eurifaesa), en Quinto es hija de la Noche ${ }^{5}$, como Hémera en el poeta de Ascra (y Éter, Th. 124; su padre es Érebo);

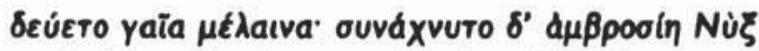

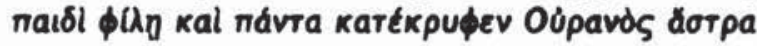

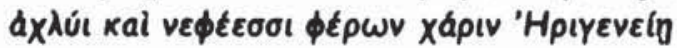

En consecuencia, Eos Erigenía abandona el segundo plano al que la relega Homero, por más que el influjo de éste quede claro ${ }^{6}$, y deviene diosa del dia ${ }^{7}$ que no sólo suplica, como en Ovidio (Met. VIII 576 ss.) ${ }^{8}$,

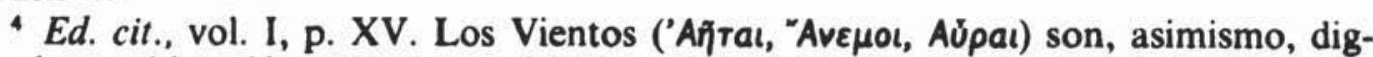
nos de consideración por sus apariciones en contextos específicos (como conductores de las almas de los héroes: QS, I 253, II 550 ss., IV 5 s.; cf. al Sueño y la Muerte con esta función en $\mathrm{Il}$. XVI 681 s.) y por su simbolismo: "parce qu'ils symbolisent la nature incorporelle des dieux" (F. Vian, ed. cit., vol. I, p. XV). Todo ello está en consonancia con las creencias populares de época imperial (algunas impregnadas de estoicismo). Es interesante también el papel funerario de las Harpías (QS, X 395) y la recurrencia a Alív (cf. F. Vian, ed. cit., p. XVII, n. 2, y p. XVIII; y A. J. Festugière. La révélation d'Hermès Trismégiste, vol. IV, París 1954, p. 180).

${ }^{5}$ Cf. Tzetzes, Posthom. 234 ss. (sobre todo, 285). Según Vian (ed. cit., vol. I, p. 52, n. 2) esta filiación dificilmente puede tener su origen en la Etiópida. Otra alteración en la genealogía la trataré al hablar de las Horas e, igualmente, cabe citar el caso de las Moiras. En Hesíodo (Th. 217) son hijas de la Noche (o de Zeus y Temis, Th. 904 y cf. Apollod., I 3, 1), mientras en QS, III 756, se las llama Xáous lepoĩo Эúyatpes.

${ }^{6}$ QS, I 830. Cf. F. Vian, ed. cit., vol. I, p. 44, n. 1. Quinto juega con los prototipos homéricos combinándolos para innovar por este procedimiento: cf., por ejemplo, Il. VIII 1, XI 1 (=Od. V 1), Il. XIX 1, etc., y QS, VI 1 ss.

7 Cuya gruta se halla en los confines de la tierra desde donde el sol se levanta:

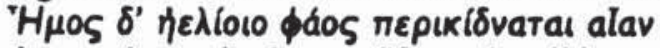

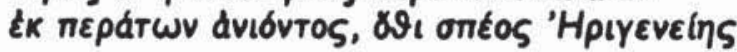

En LSJ (s. u. $\eta \dot{\omega} s$ I. 3.) se da el significado de «life» al sustantivo en QS, X 431...

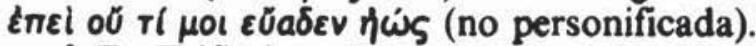

${ }^{8}$ En Trifiodoro (30 ss.), Eos se limita a cubrir el cielo con una nube en señal de luto, dato que se lee en QS, II $542 \mathrm{~s}$. 
sino que amenaza con desentenderse de su cometido (aunque finalmente Zeus la disuada; QS, II 661 ss.) y dejarlo, para mal de inmortales y hombres, en manos de su rival, Tetis:

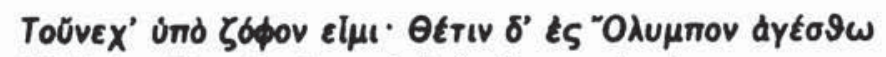

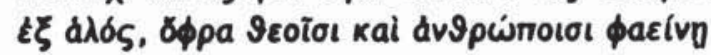

(II 619 s.)

Por otro lado, entre los epítetos que Quinto le aplica ${ }^{9}$ no están ni

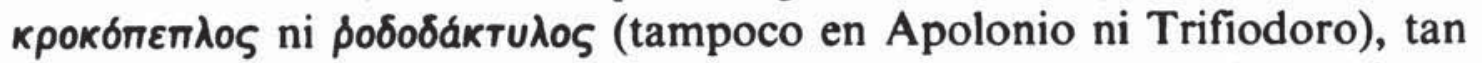

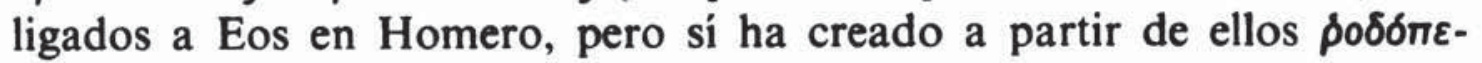
$\pi$ तos (hápax, III 608).

3. A continuación, merecen unas líneas las Horas con el fin de hacer hincapié en diversos aspectos.

El único paralelo posible con Homero es el de X 334 ss. Ahí se mencionan cuatro $\dot{\alpha} \phi \phi i n o \lambda o l$ (v. 336) de Hera, lo que trae a la memoria el dato de $I l$. VIII 433 donde las Horas desuncen los caballos de esta misma diosa ${ }^{10}$. Aun así las diferencias son notables, puesto que Homero no da su número y les adjudica siempre una función secundaria (cuidan la puertas del cielo: Il. V 749, VIII 393; cf. Pi., O. IV 2). Desde Hesíodo

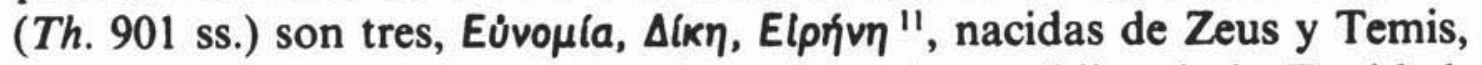
hermanas de las Moiras. Su carácter ético (como hijas de la Equidad, de la Ley) es posterior al originario de representar las estaciones del año ${ }^{12}$.

Quinto, por su parte, nos revela dos concepciones diferentes. Por una de ellas, la de menos aparición en los Posthomerica (sólo en los versos citados arriba), las servidoras de Hera patrocinan las estaciones ${ }^{13}$,

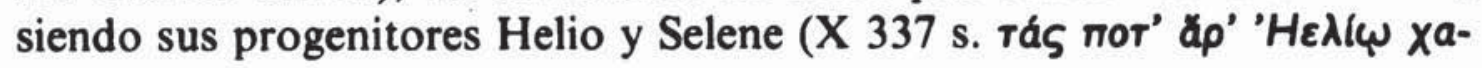

9 Unos son debidos a la tradición homérica, se apliquen o no concretamente a

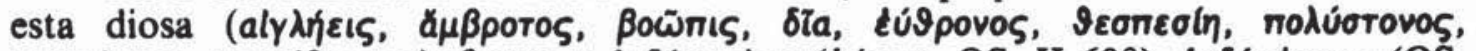

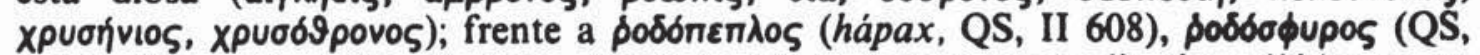

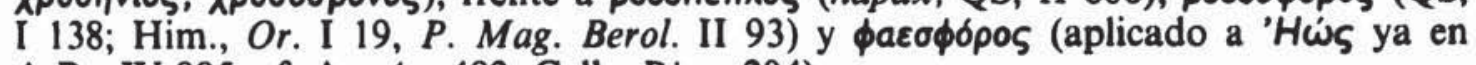
A.R., IV 885; cf. A., Ag. 489; Call., Dian. 204).

${ }^{10}$ En Ovidio (Met. II $118 \mathrm{~s}$.) es el Sol quien les ordena enganchar los caballos.

"Pausanias (IX 35, 1) transmite otros nombres: Carpo, Talo (a la que los atenienses rinden culto).

${ }_{12}$ H. J. Rose, A Handbook of Greek Mythology, Londres 1972 (1." ed. 1928), p. 124.

${ }^{13}$ Cf. X 340 ss.:

†े $\delta^{\prime} \varepsilon t \varepsilon \rho \eta \eta$

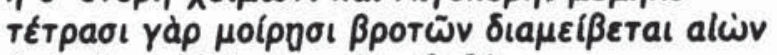

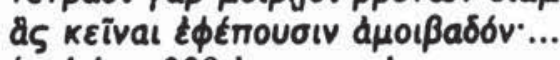

Después del v. 339 hay una laguna «où étaient mentionnés les attributs des troits premières Saisons» (F. Vian, ed. cit., vol. III, p. 30, n. 2). 


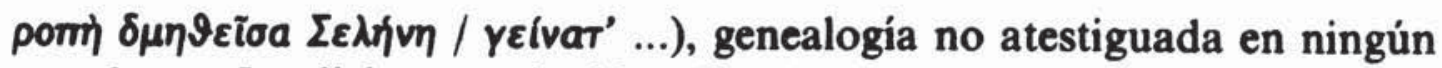
otro lugar. Lo dicho permite identificarlas con las Horas, aunque el texto silencie este nombre.

De acuerdo con la segunda noción (I 49 ss., II 501 ss., 594 ss., 657

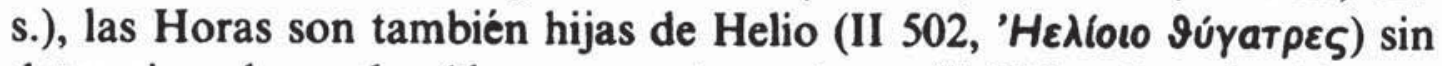

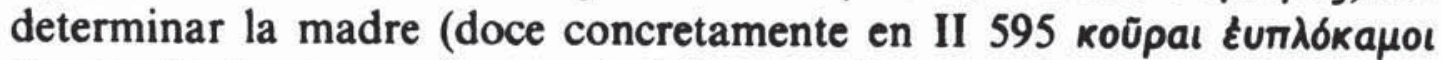
$\delta v o<$ raí $>\delta \varepsilon \kappa a$ ), con la característica común en cada uno de los pasajes de constituir el séquito habitual de Eos, diosa del Día, según vimos. Por ello, "correspondent aux douze stations que le soleil parcourt soit pendant sa route diurne soit plutôt tout au long de l'année» ${ }^{14}$, y están asociadas, pues, a los doce signos zodiacales (por ende, a las estaciones de nuevo):

$$
\begin{aligned}
& \text {... T็̃oเv } \mu \varepsilon \mu \eta \lambda \varepsilon v
\end{aligned}
$$

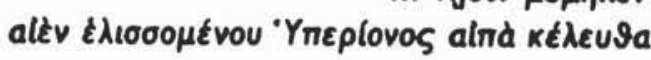

(II 595 s.; y cf. II 501 ss.)

No considero oportuno identificar a estas divinidades con las conocidas Heliades, como defiende F. Vian ${ }^{15}$. Estas últimas son las hermanas de Faetonte, por el que vierten lágrimas que se convierten en ámbar en V 626 ss. Que sean como aquéllas hijas de Helio (V $626^{\text {' } H \varepsilon \lambda l o ı . . . ~}$ Эuүarpũv; y de Climene, cf. Ov., Met. II 330 ss., Higino, Fab. 152 y 154) no es razón para confundirlas, ya que Quinto ni hace referencia a Eos en estos hexámetros ni a su número (tres en Schol. Od. XVII 208, o siete en Higino, Fab. 154).

Queda por aclarar la mención de las Horas en IV 134 ss., en el discurso que Néstor pronuncia en honor de Aquiles, cuando se centra en la boda de Tetis y Peleo. La tradición informa de la presencia de los dioses en la ceremonia ${ }^{16}$, pero de la asistencia de las Horas al acontecimiento sólo habla Quinto. Que las haya tenido en cuenta el poeta puede ser un indicio de su creciente valoración o quizá un mero reflejo de contextos como el de h. Ap. 189 ss. ${ }^{17}$, donde Musas, Gracias y Horas

14 F. Vian, ed. cit., vol. III, p. 30, n. 4 (en Notas complementarias, p. 208). Para el Zodíaco, el sol y las estaciones en la tradición, cf. Arat., 545 ss. (552 ... déķoviat

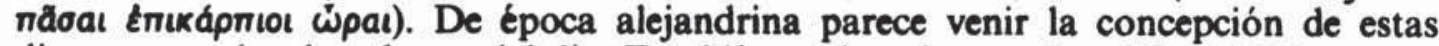
diosas como las doce horas del día. También se descubre en Ov., Met. II $25 \mathrm{~s}$.

is Ed. cit., vol. I, p. XV, y p. 14 , n. 3.

${ }^{16}$ Explicitamente ya en Il. XXIV 62 y cf. Pi., P. III 89 ss.; A.R., IV 807 s.; Apollod., III 13,5; Catulo, LXIV 268 ss., etc.

17 También hay representaciones artísticas como la señalada por F. Vian, ed. cit., vol. I, p. 141, n. 5 (en Notas complementarias, p. 175). Cf., acerca de las Gracias y las Horas, Paus., II 17,4; VII 5,4, etc. 
intervienen de forma conjunta (cf. QS, IV 135, 140, 141), aunque el cometido de las Horas en el himno homérico es danzar junto con las Gracias, Harmonia, Hebe y Afrodita (v. 194 ss.), mientras que en Quinto asumen la ya comentada función de servidoras, pero aquí sin alusión a

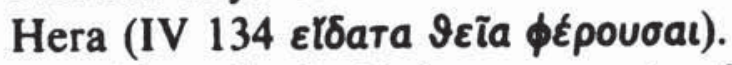

El interés de Quinto por estas figuras (y por la de Eos), que acaso se vislumbre en el terreno del vocabulario ${ }^{18}$, puede deberse tanto a su propia iniciativa ${ }^{19}$, como al influjo de las ideas sobre astrología (muy en boga desde el período helenístico hasta el siglo II d.C. y la baja antigüedad) y al de las especulaciones, mitología y misticismo con ella relacionados ${ }^{20}$. Bien es verdad, no obstante, que Quinto mantiene el sabor homérico en su obra sin que estas influencias causen desconcierto y, desde luego, no llega a los extremos, valga el ejemplo, de Nonno ${ }^{21}$.

4. Por último, me detendré en la figura de Temis, para cuyo encumbramiento en los Posthomerica hay que contar presumiblemente con esas tendencias moralizadoras que se rastrean en Quinto, pero que son superficiales, no afectando, pues, al conjunto $y$ al fondo de la obra ${ }^{22}$.

Una vez más estamos ante una diosa que no destaca en Homero, si bien es verdad que en él, además de participar en el banquete de los dioses (Il. XV 87 s.; presidiéndolo a instancias de Hera en 93 ss.; cf. $h$. Ap. 124), de lo que es un reflejo QS, IV 136 s., la vemos próxima a Zeus, en la función nada trascendente de mensajera (Il. XX 4 ss.; y cf.

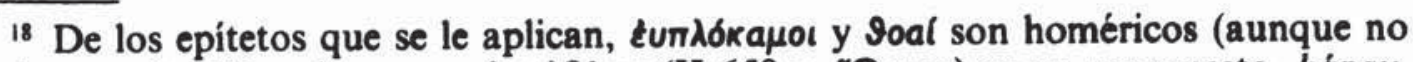

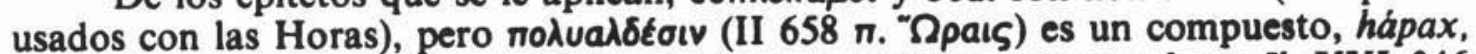
creado por nuestro autor, quizá inspirado en veoaגorís que es u.l. en Il. XXI 346

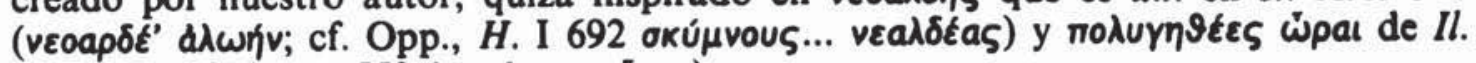

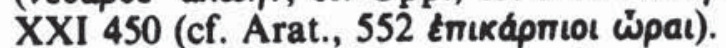

19 Coluto, por ejemplo, menciona a las Horas (v. 344 s.) una sola vez y sin mayor trascendencia.

${ }_{20}$ La Estoa, hay que subrayarlo, tampoco desdeñaba la astrología y fue Panecio, según el testimonio de Filón de Alejandría (Fr. 74), la única excepción en cuanto que rechazaba los pronósticos astrológicos. Recuérdese la célebre teoría estoica de la

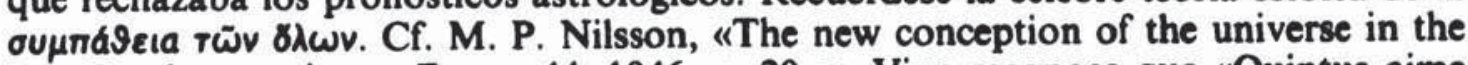
late Greek paganism», Eranos 44, 1946, p. 20 ss. Vian reconoce que "Quintus aime la mythologie astrale» (ed. cit., vol. I, p. 14, n. 3), y de ahí que se sirva de alegorías cósmicas. Es curioso que en Orph. H. XI a Pan se le considera dpuovínv кóoroto

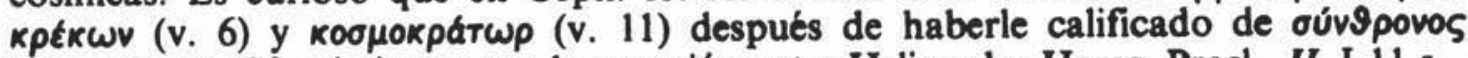
¿spaı (v. 4). Cf. asimismo para la conexión entre Helio y las Horas, Procl., H. I $11 \mathrm{s.}$

${ }_{21}$ Nonno ha recogido y utilizado los dos grupos de Horas:

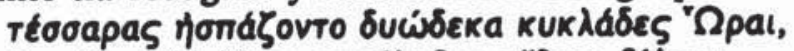

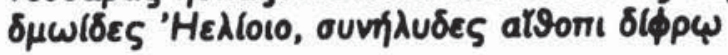

(D. XII 17 s.)

Cf., en general, Nonn., D. XI 484 ss. y XII 1 ss.

22 Cf. F. Vian, ed. cit., vol. I, p. XXXVII. 


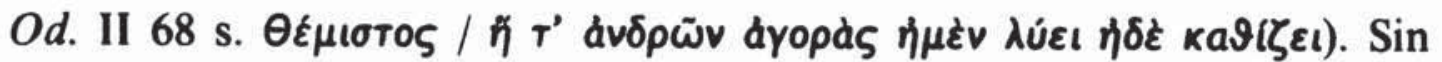
embargo, esa proximidad ha sido desde muy pronto recalcada, hasta el punto de alcanzar el puesto de personaje muy venerable y el de consejera del Crónida ${ }^{23}$. En esta línea, que arranca principalmente de Hesíodo, hay que situar a Quinto. Ha de hacerse, no obstante, una salvedad. Si Temis ha subido peldaños en los poemas hesiódicos, no es menos cierto que la novedad más llamativa corresponde a la figura de Dice, desconocida para Homero, a la que nos referimos arriba como una de las Ho-

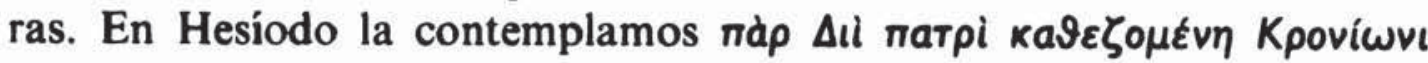
(Op. 259; cf. A., Fr. 530), respetada por los Olímpicos, como prueba irrefutable de que el sentido de la moralidad divina ha cambiado respecto a Homero y ha recibido desde este momento un impulso que perdura en Esquilo, Eurípides, Platón y los estoicos ${ }^{24}$.

En Quinto no sólo aparece $\Delta i k \eta$ en V 46 y XIII 378, sino que a Temis se le ha transferido el sobresaliente papel ${ }^{25}$ que aquélla desempeña en la tradición (como se comprobará al revisar los textos) y así ambas figuras representan a una misma diosa Justicia. Pero antes es de resaltar el hecho de que, además de las ya aludidas aportaciones de ascendencia estoica, el conocimiento de Hesíodo se plasma en diversos lugares de la

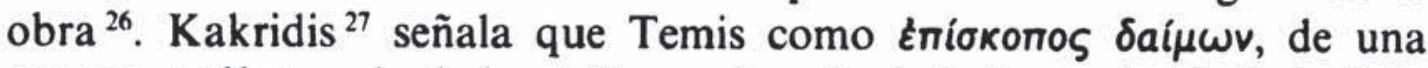

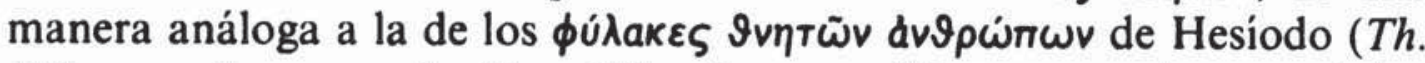
123 ss. y cf., acerca de $\Delta i k \eta, 258$ ss.), se manifiesta por primera y única vez en Quinto:

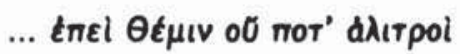

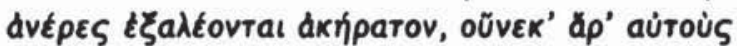

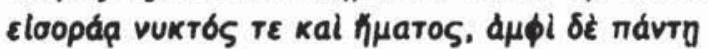

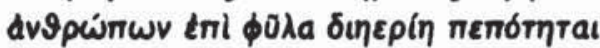

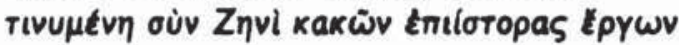

(XIII 369 ss.)

${ }^{23}$ Cf. de nuevo Hes., Th. 16, 135, 901 ss. (ya citados al hablar de las Horas), $h$. Ap. $93 \mathrm{~s}$. (con el sobrenombre 'IXvaín, v. 94, ya por su culto en Icna en Tesalia, cf. Str., IX 5, 14, ya, según otros, por ser "la que rastrea", cf. lxvdóal = lxveúw; cf. la misma epiclesis en Lyc., 129). En AP XII 31 (Phan.) se jura por Temis. Su papel de consejera está explícito en $h$. Hom. XXIII 2 s., o en Pi., $O$. VIII 22 . En las Ciprias, según Proclo (Chr. I), Zeus deliberaba con Temis sobre la guerra de Troya. Como dea uaticinans está en A., Eu. 2 ss. (en la sucesión Tierra, Temis, Febe, Febo, del oráculo de Delfos) o Pi., P. XI 9 (cf. Pi., I. VIII 35). 1967.

${ }^{24}$ Cf. en general el estudio de F. Solmsen, Hesiod and Aeschylus, Nueva York

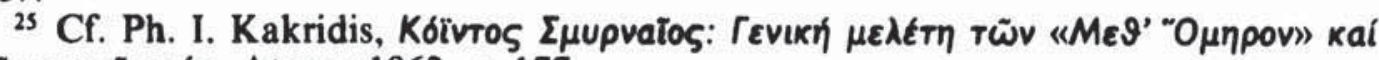

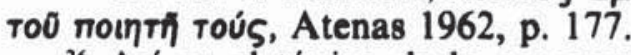

${ }^{26}$ Así en el tópico de la consagración poética (QS, XII 306 ss. $\sim$ Hes., Th. 22 s.; pero en Quinto en primera persona al igual que en la invocación a las Musas de Il. II 484 ss.) o el tema del «Monte de la Virtud» (QS, V 49 ss. Hes., Op. 287 ss.; y cf. QS, XII 292 ss., XIV 195 ss.), además de los muchos paralelos que se espigan a lo largo de los Posthomerica, puntualmente señalados por Vian en su edición.

27 Loc. cit. 
Relacionada con Zeus también está Temis en VIII 70 ss., donde los hombres que traspasan sus dictámenes provocan el enojo de aquél, en una escena similar a la de Il. XVI 385 ss., en la que Zeus se encoleriza

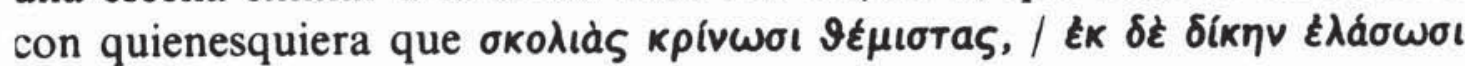
(v. 387 s.).

Al influjo hesiódico, sin embargo, debe sumarse la idea homérica, con ostensibles reflejos en los Posthomerica ${ }^{28}$, de $9 \varepsilon \hat{\mu} \mu \varsigma$ como vocablo en que se encierra la noción del orden establecido, de lo que se permite

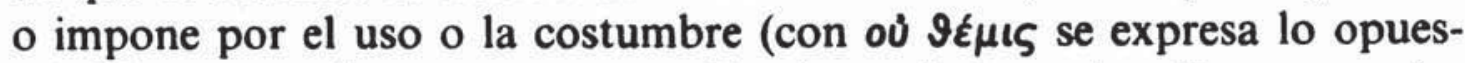
to). No es extraño, entonces, que Temis recrimine a los dioses cuando, transgrediendo su condición, se rebajan a contender por los efimeros mortales:

Con Dice Quinto apela decididamente a Hesíodo. En V 46 supervisa las escenas de la paz cinceladas en el escudo de Aquiles (cf. Hes., Sc. 139 ss.) poco antes de que se describa el monte de la Virtud, también de raices hesiódicas. Por otro lado, en XIII $377 \mathrm{~s}$. da cumplimiento (Td

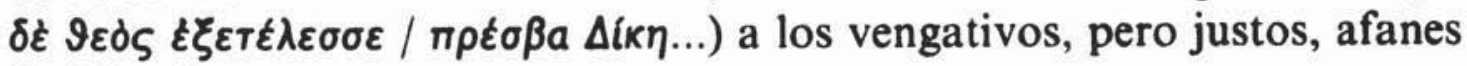
de Menelao.

Atendiendo al vocabulario, hay que anotar que Temis no sólo es

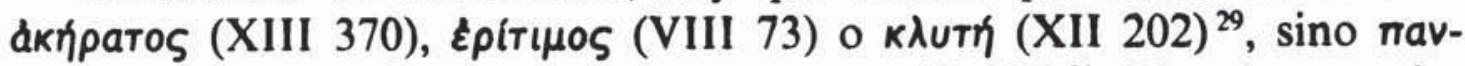

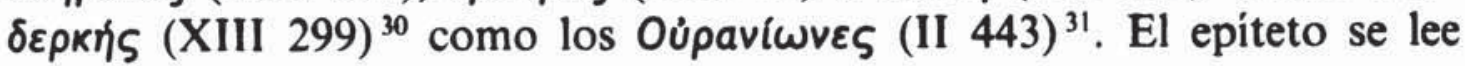

${ }^{28}$ Cf. Il. II 73, IX 33, 134, etc.; Od. III 45, 187, etc.; QS I 753, II 160, VI 58,

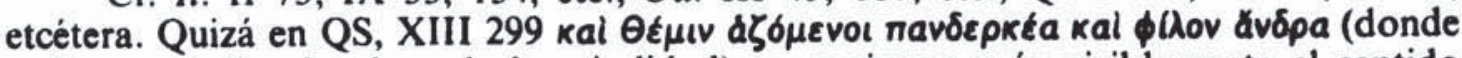
está por medio el enlace de hospitalidad) se conjugan más visiblemente el sentido

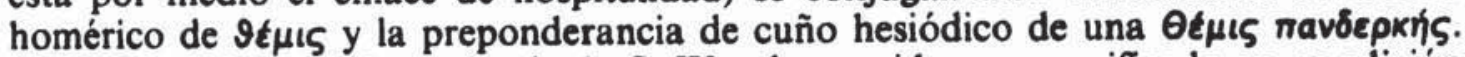
Cf. QS, I 753 Eoti $\vartheta_{\varepsilon \mu L}$, donde A. S. Way la considera personificada en su edición (Quintus Smyrnaeus. The Fall of Troy, Londres [Loeb] 1913, repr. 1984), que sigue la de Köchly (de 1850) con enmiendas de Zimmermann.

29 Los tres adjetivos son homéricos aunque no se aplican a Temis. Para QS, XIII

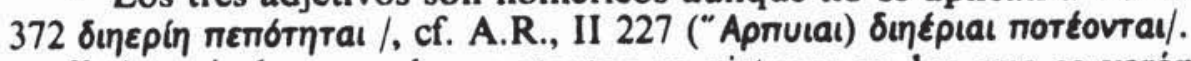

${ }_{30}$ Apoyándome en los contextos ya vistos y en los que se verán, considero que esta forma no hace alusión a su papel de dea uaticinans señalado en $\mathrm{n}$. 23 , sino que debe responder a una primacía singular de la diosa en Quinto.

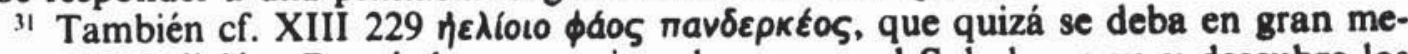
dida a la tradición. Recuérdese, por ejemplo, que es el Sol el que ve y descubre los amoríos de Ares y Afrodita: Od. VIII 271 y 302; Luc., DDeor. 17, 1, y cf. Ov., Met.

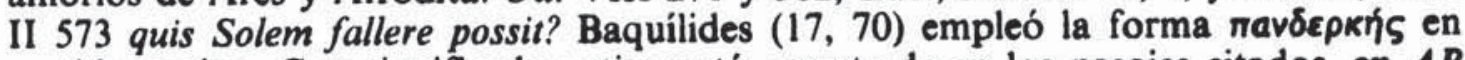
sentido pasivo. Con significado activo está, aparte de en los pasajes citados, en AP IX 525, 17. 


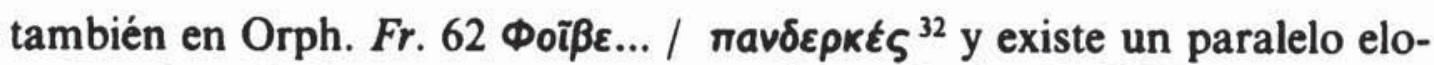
cuente de todo lo que vengo comentando en Orph. $H$. LXII 1 ss.:

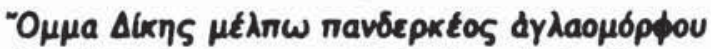

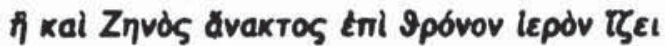

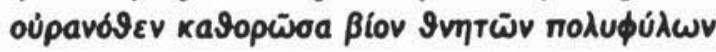

Zeus es navrómtas (A., Supp. 140, Eu. 1045; S., OC 1085; cf. navómтク Orph. Fr. 170), un compuesto de significado comparable a nav-

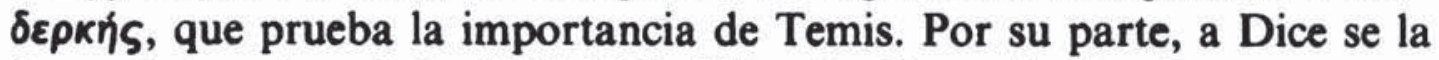

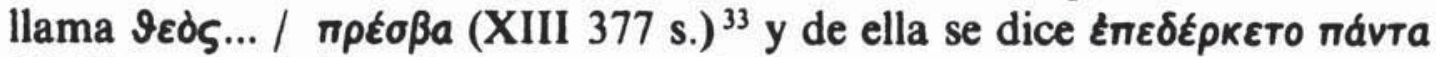
(V 46, y recuérdese el texto antes citado, XIII 369 ss., acerca de Temis

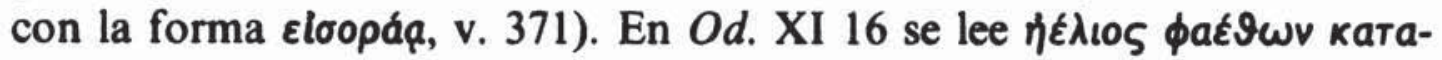

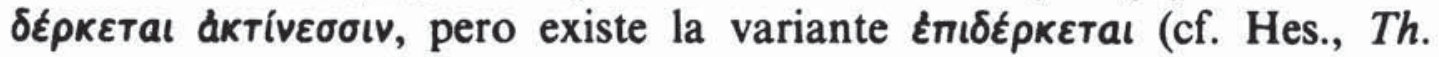

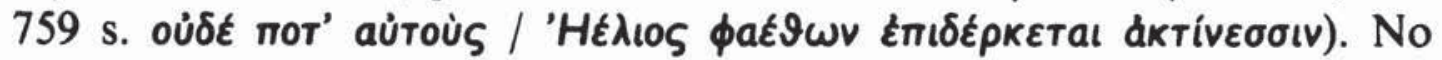
obstante, el verdadero sentido del verbo en el verso citado de Quinto debe buscarse en Hes., Th. 267 ss.:

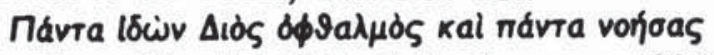

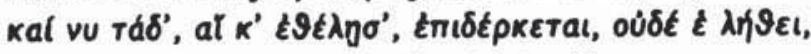

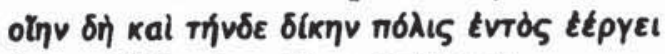

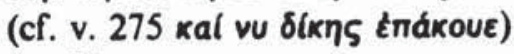

Que $\varepsilon m \_\delta \rho к о \mu a \imath$ contiene unos matices precisos se deduce del hecho de que Quinto lo ha empleado con figuras señeras en los Posthomerica: Zeus (I 185, y cf. A.R., II 1179), Erigenía (II 617) y Aisa (XII 473).

En definitiva, parece que Hesíodo ha desempeñado un papel descollante en la configuración de Temis y Dice en la obra de Quinto, pero hay que contar igualmente con el dato de que la concepción hesiódica se adapta muy bien a las ideas de la época en que el poeta se mueve y, en concreto, a las estoicas ${ }^{34}$ que tanta influencia han ejercido sobre el quehacer de Quinto.

\section{Francisco antonio Garcia Romero}

${ }^{32}$ Es muy posible la identificación aqui de Febo Apolo con el Sol, que, tras surgir en el siglo v a. C. (E., Fr. 781, 11 ss., y con reservas en A., Supp. 212 ss.; Hes., Th. 859; cf. Call., Fr. 302 Pf.), es frecuente en los escritos órficos: Orph. $H$. XXXIV

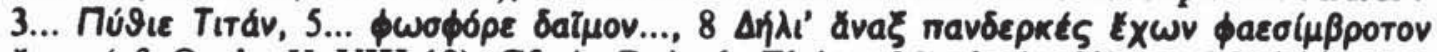
$\delta \mu \mu a$ (cf. Orph. H. VIII 12). Cf. A. Ruiz de Elvira, Mitologia Clásica, Madrid 1975, p. $81 \mathrm{~s}$.

${ }_{33}$ Tpéoßa, que sólo se aplica a Dice en Quinto, en Homero casi siempre acompa-

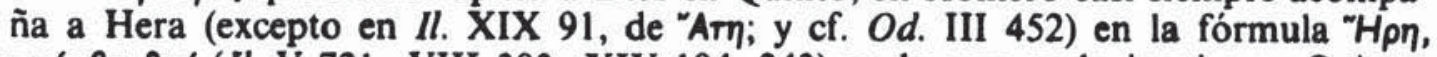

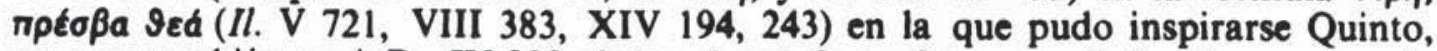

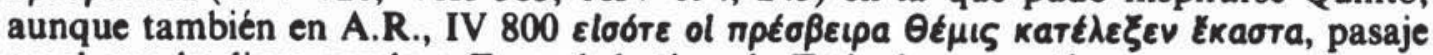
en el que la diosa revela a Zeus el destino de Tetis, lo que está en consonancia con su facultad tradicional de vaticinar.

34 La divinidad estoica se caracteriza por la supervisión de los actos humanos:

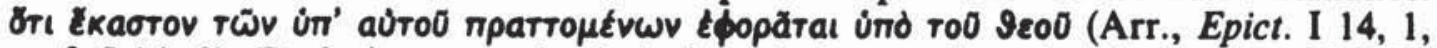
y cf. I 14, 9). De la importancia de la justicia hay testimonios de interés: $S V F$ III 256 y 264. Junto a Zeus se halla en el Himno a Zeus de Cleantes (SVF 537, 35):

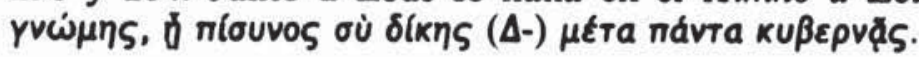

